\title{
O PAPEL DAS INTERAÇÕES SOCIAIS E DE ATIVIDADES PROPOSTAS PARA O ENSINO- APRENDIZAGEM DE CONCEITOS QUÍMICOS
}

\section{The role of social interactions and of proposed activities in the teaching and learning of Chemistry}

\author{
Juciene Moura de Nascimento $^{1}$. Edenia Maria Ribeiro do Amaral ${ }^{2}$
}

Resumo: Este trabalho teve como objetivo analisar o papel das interações sociais e de atividades didáticas propostas em aulas de Química. Apresenta discussões com base nas teorias sociointeracionistas de Vygotsky e Leontiev, suas implicações e abordagens nos diversos processos de construção de conceitos. O trabalho foi realizado em uma Escola Pública de Pernambuco, onde foram observados doze alunos, os quais participaram de diferentes tipos de atividade em sala de aula. Essas atividades, realizadas em pequenos grupos, sob a supervisão da professora, foram analisadas considerando-se como relevantes as oportunidades de interação e discussão que as mesmas possam ter possibilitado entre os alunos durante as aulas. Os resultados apontaram para a importância do planejamento de atividades que promovam um processo coletivo, cooperativo e interacionista de ensino e aprendizagem, reforçando o papel do outro na formação mais ampla dos alunos e contribuindo para uma melhor significação dos conceitos científicos.

Palavras-chave: Interação social. Atividade didática. Ensino de Química.

\begin{abstract}
This study aimed to analyze the role played by social interactions and by didactical activities in chemistry classes. We have taken into account aspects of sociointeractionist theory such as proposed by Vygotsky and Leontiev, and their implications and approaches applied to the processes for concept formation. The investigation was carried in a Public School of Recife, PE - Brazil, where different types of didactical activities were proposed in the chemistry classroom. These activities were performed by students in small groups under teacher supervision and analyzed by considering as relevant opportunities for interaction and discussion among students which started from tasks demanded during the classes. The results pointed out the importance in planning activities which encourage students to engage in a collective, cooperative and interactional process in teaching and learning, reinforcing the role played by pairs in the learning and contributing from students in making scientific concepts meaningful.
\end{abstract}

Keywords: Social interactions. Didactical activities.Chemistry teaching.

\footnotetext{
${ }^{1}$ Secretaria de Educação e Cultura do estado de Pernambuco, Rede Pública de Ensino. Recife, PE, Brasil. Avenida Afonso Olindense, 1513, Várzea, Recife, PE, Brasil. jucienemoura@yahoo.com.br ${ }^{2}$ Departamento de Química, Programa de Pós-Graduação em Ensino de Ciências, Universidade Federal Rural de Pernambuco. Recife, PE, Brasil.
} 
Nascimento, J. M.; Amaral, E. M. R.

\section{Introdução}

Este trabalho consiste de uma análise das interações ocorridas em sala de aula no sentido de promover a aprendizagem de conceitos químicos pelos alunos, tendo como foco questões sobre o papel das atividades didáticas e do trabalho em grupo como um aspecto relevante nesse processo. Para isso, tomamos como base teórica algumas considerações da teoria sociointeracionista de desenvolvimento e aprendizagem dos indivíduos, como a proposta por Vygotsky (2007) e continuada por Leontiev $(1978,1979)$. A perspectiva sociointeracionista traz uma concepção de que o homem se constitui como ser humano a partir das relações que estabelece com o outro. Diante disso, optamos por discutir a importância das interações aluno-aluno que são estabelecidas no processo de ensino-aprendizagem, considerando aspectos tais como: a formação de grupos de trabalho, o papel das atividades propostas para a construção do conhecimento e fatores que influenciam a aprendizagem e o desenvolvimento individual no contexto da discussão coletiva.

O processo de ensino-aprendizagem vincula um conjunto de ações pedagógicas que, direta ou indiretamente, influenciam no desenvolvimento do aluno. Tais ações, caracterizadas basicamente por atividades de ensino, encontram-se ainda inseridas num contexto educacional que prioriza o acúmulo de informações descontextualizadas e cujos procedimentos resultam num distanciamento entre professor e aluno. Nesse sentido, muitas vezes, essas ações delimitam o rendimento do aluno estabelecendo o ensino como uma prática desvinculada do processo de aprendizagem.

Em geral, na sala de aula, são constituídas interações sociais que, muitas vezes, não são consideradas como um aspecto relevante para o desenvolvimento cognitivo do aluno, refletindo uma concepção de que este espaço é povoado de espectadores. A pouca importância dada às oportunidades de interação nas quais os alunos podem se posicionar sobre os conteúdos em foco acaba por dificultar uma aprendizagem significativa. De outro modo, o professor que apresenta uma postura distinta e trabalha com uma dinâmica interativa, tende a considerar essenciais os aspectos sociointerativos dos indivíduos envolvidos no processo de ensino-aprendizagem, levando-os a uma forte participação na construção e reconstrução dos conceitos. Diante disso, e considerando a experiência profissional da professora pesquisadora envolvida neste trabalho, que regularmente introduz práticas coletivas de ensino-aprendizagem na sua ação docente, levantamos as seguintes questões: como podemos identificar relações entre ações que promovem interações sociais e as atividades didáticas coletivas propostas e desenvolvidas em aulas de Química? Como essas relações podem influenciar o processo de ensino-aprendizagem? Como as atividades em grupo podem melhor contribuir para o processo de ensino-aprendizagem?

No intuito de obter possíveis respostas para as questões acima, neste trabalho, buscamos discutir ideias fundamentais da teoria interacionista de Vygotsky (1896-1934) e da teoria da atividade proposta por Leontiev (1903-1979), cujas concepções, influenciadas pelo pensamento marxista e pelo materialismo histórico-dialético, dentre outros, estabelecem que a aprendizagem e o desenvolvimento resultam das interações sociais e das trocas com indivíduos mais experientes, nas quais a mediação se dá pelas atividades realizadas. 
O papel das interações sociais e de atividades ...

\section{Interação e atividade}

Em sua extensa obra, desenvolvida em poucos anos, Vygotsky enfatiza a estreita relação entre aprendizado e desenvolvimento, ao conceber que o desenvolvimento humano em sua plenitude é dependente das possibilidades de aprendizagem colocadas à disposição do indivíduo, e estas possibilidades são aquelas fornecidas pelo grupo cultural de origem. Segundo ele, "o aprendizado humano pressupõe uma natureza social específica e um processo através do qual as crianças penetram na vida intelectual daqueles que as cercam" (VYGOTSKY, 2007, p. 100). Vygotsky (2007) defende ainda que o desenvolvimento é mais lento do que a aprendizagem, e que esta, sendo bem estruturada, pode ativar e resultar em processos de desenvolvimento.

Vygotsky (VYGOTSKY, 1989, apud PINO, 2000) aponta, repetidas vezes, para o papel do outro na constituição cultural do homem. Para ele, "nós nos tornamos nós mesmos através dos outros" (VYGOTSKY, 1989, p. 56 apud PINO, 2000, p.54), evidenciando, neste princípio, a essência do processo de desenvolvimento cultural na sua forma puramente lógica. Essa expressão pode ser dita de outra forma: é pelo outro que o $e u$ se constitui em um ser social com sua subjetividade. Sendo assim, Vygotsky (2007) reafirma a concepção de que todo homem se constitui como ser humano pelas relações que estabelece com os outros. Para ele, desde o nosso nascimento somos socialmente dependentes dos outros e entramos em um processo histórico que, de um lado, nos oferece os dados sobre o mundo e visões sobre ele e, de outro, permite a construção de uma visão pessoal sobre este mesmo mundo.

Dessa forma, compreendemos que a abordagem vygotskiana enfatiza um sujeito do conhecimento não apenas passivo, moldado por regulações externas, e nem tampouco apenas ativo, moldado por regulações internas, mas, um sujeito interativo e dinâmico em suas escolhas e atitudes, cuja história de vida vai sendo construída à medida que, socialmente, integrase a outras histórias de vida, incorporando valores, hábitos e experiências, assim como a própria linguagem daqueles com quem interage. Nesse sentido, a perspectiva sociointeracionista configura a aprendizagem num cenário no qual as relações sociais constituem o elemento fundamental do desenvolvimento e, por essa razão, a coletividade viabiliza um espaço para o diálogo e para a consolidação de práticas cotidianas, potencializando papéis e avanços cognitivos a cada um. Turra e Santos (2002, p. 18) afirmam que "ninguém sabe tudo, todos sabemos algo", enfatizando a importância do papel do outro na construção coletiva do conhecimento.

Tomando por base a perspectiva vygotskiana, consideramos que as interações em sala de aula são fundamentais para a formação do aluno, pois, tendem a promover uma troca significativa de conhecimentos e experiências que influenciam os processos de maturação cognitiva de cada um. As parcerias aluno-aluno e professor-aluno permitem a ampliação do universo social educacional do aluno, facilitando a aprendizagem dos conceitos, e, portanto, as interações sociais constituem parte importante do processo de ensino-aprendizagem. Elas são, segundo os pressupostos sociointeracionistas, a chave que facilita a construção do conhecimento.

Os seguidores de Vygotsky apresentaram novas formulações que incluem distinções e complementaridades em relação às bases teóricas iniciais. Em parceria com Vygotsky, Leontiev e Luria estenderam suas pesquisas sobre a base teórica da Psicologia histórico-cultural em 
Nascimento, J. M.; Amaral, E. M. R.

relação a temas como: origem e desenvolvimento do psiquismo, processos intelectuais, emoções, consciência, atividade, linguagem, desenvolvimento humano e aprendizagem conforme apontam alguns trabalhos desenvolvidos por pesquisadores tais como Moura (2002), Sforni (2003) e Cedro (2004). Em seguida, estudos desenvolvidos sobre a atividade humana culminaram na formulação da teoria da atividade, ampliada posteriormente por outros autores, como: Galperin (psicologia infantil), Boyovich (psicologia da personalidade), Elkonin (psicologia do desenvolvimento), Zaporoyetz (psicologia da evolução) e Levina (psicologia da educação). Núñez e Faria (2004) destacam que é importante deixar claro que Vygotsky não discute uma teorização sobre atividade como uma condição necessária para a formação de conceitos científicos, mas, Leontiev, com base nas experiências e pesquisas de Vygotsky e nos princípios do materialismo dialético e histórico, elabora uma teoria sobre a atividade humana. É importante destacar que a Teoria da atividade, proposta por Leontiev (1983), tem sido relevante objeto de estudo no Centro de Estudios para el Perfeccionamiento de la Educación Superior da Universidade de Havana, em Cuba. Ressalta-se, ainda, que tais estudos têm sido amplamente difundidos em países latino-americanos, inclusive em universidades brasileiras.

Desse modo, estudos recentes dos processos de aprendizagem em grupo concentram-se nos pressupostos teóricos de Leontiev, propondo a ideia de que a construção do conhecimento em um grupo está relacionada com as atividades realizadas por este. Nessa perspectiva, Leontiev (1979) propôs a atividade como a unidade básica para a compreensão do psiquismo e das relações sociais, e desenvolveu a teoria da atividade buscando superar as lacunas apontadas às ideias de Vygotsky acerca da formação das funções psicológicas superiores. Para Leontiev (1983), o mais importante são os tipos específicos de atividade que requerem o uso da linguagem.

Sendo assim, compreendemos que, na concepção sociointeracionista, a atividade é um conceito-chave do processo de mediação. É ela que estabelece a relação do homem com a realidade objetiva, permitindo ao mesmo não reagir mecanicamente aos estímulos do meio, mas, por meio das suas atividades, se pôr em contato com os objetos e fenômenos, atuando sobre eles, transformando-os, e transformando também a si mesmo.

A atividade humana é global, mas ela se desdobra em distintos tipos concretos de atividade, cuja diferenciação é dada pelo seu conteúdo objetal. Segundo Leontiev (1983), cada tipo de atividade possui um conteúdo perfeitamente definido de necessidades, motivos, tarefas e ações. Por exemplo, o conteúdo objetal da atividade do jogo é substancialmente diferente da atividade de estudo ou da atividade profissional. O que distingue uma atividade de outra é o objeto da atividade, que confere à mesma determinada direção (LEONTIEV, 1983 apud LIBÂNEO, 2004). A atividade humana constitui-se, portanto, de uma estrutura complexa cujos componentes (necessidades, objetivos, ações, operações) estão interligados e em constante estado de transformação e mudança. Tanto a atividade externa, regulada por sistemas sociais de relações, quanto a atividade interna, regulada por estruturas psicológicas peculiares ao indivíduo, surgem de necessidades que, posteriormente, vão sendo convertidas em motivos para ações. Cada ação pode ser realizada de diversas maneiras, e a essas maneiras é dado o nome de operação. Portanto, para alcançar um determinado objetivo, é necessário realizar uma ação através de várias operações. Assim como as ações se relacionam com seus objetivos, as operações são relacionadas às condições de realização dessa ação (LEONTIEV, 1979; OLIVEIRA, 2003). 
O papel das interações sociais e de atividades ...

Leontiev (1978) compreende que o sujeito, enquanto indivíduo, nasce com várias necessidades. As necessidades, enquanto forças internas, só podem ser realizadas na atividade. Em outras palavras, a necessidade aparece, em princípio, só como uma condição, um prérequisito para a atividade, porém, quando o sujeito começa a agir, ocorre sua transformação e a necessidade deixa de ser aquilo que era virtualmente em si mesma. Quanto mais prossegue o desenvolvimento da atividade, mais esse pré-requisito é convertido em seu resultado (LEONTIEV, 1978).

Em resumo, as necessidades vão se modificando à medida que os objetos se modificam dentro das atividades - a variedade e a complexidade dos objetos direcionam a atividade. Para Leontiev (2001), o ciclo que vai de necessidades a objetos se consuma quando a necessidade é satisfeita, sendo que o objeto da necessidade ou motivo é tanto material quanto ideal. Para que estes objetivos sejam atingidos, são requeridas ações. O objetivo precisa sempre estar de acordo com o motivo geral da atividade, mas são as condições concretas da atividade que determinarão as operações vinculadas a cada ação. Leontiev (2001) define como atividade: aqueles processos que, realizando as relações do homem com o mundo, satisfazem uma necessidade especial correspondente a ele. Por atividade, designamos os processos psicologicamente caracterizados por aquilo a que o processo, como um todo, se dirige, coincidindo sempre com o objetivo que estimula o sujeito a executar essa atividade, isto é, o motivo (LEONTIEV, 2001).

Diante da discussão colocada acima, neste trabalho, consideramos que é pela construção e reconstrução de significados que a aprendizagem ganha um sentido real em torno de todo processo educacional. Possibilitar e estimular a prática de atividades coletivas contribui para a internalização do objeto de conhecimento em sala de aula, de forma participativa, permitindo, ao sujeito, o papel ativo de seu próprio desenvolvimento. A compreensão da interação com o outro, mediada por atividades sistematizadas e em cujos motivos encontramse as necessidades pedagógicas básicas do aluno, é um fator predominantemente fundamental para as discussões aqui propostas. Dessa forma, acreditamos que atividades bem estruturadas, ou planejadas segundo as necessidades e motivos dos alunos para a aprendizagem, podem levar a processos interativos que resultem em uma aprendizagem mais significativa. Considerando os estudos de Vygotsky (2007) e de Leontiev (2001), compreendemos a relevância das relações sociais no desempenho dessas atividades, e que estas, substancialmente, medeiam a construção do conhecimento, permitindo ao professor alcançar a finalidade dos conteúdos propostos. Tanto a Teoria da Atividade quanto as discussões em torno das interações sociais e seus paradigmas vêm ao encontro dos interesses desta pesquisa e se ajustam às ações propostas na metodologia.

\section{Metodologia}

Este trabalho é parte de uma dissertação de mestrado cujo foco está centrado nas interações sociais constituídas em sala de aula e sua influência no processo de ensino-aprendizagem, e, ainda, nas implicações das atividades didáticas propostas para a ação educativa. Desse modo, a pesquisa insere-se numa perspectiva etnográfica considerando a proposição de procedimentos e técnicas utilizadas para coleta de dados. Fizemos uma opção teórica pela 
abordagem etnográfica interacional, já que esta possibilita o conhecimento de como os participantes utilizam tempo e espaço na sala de aula e definem quem pode fazer ou dizer o quê, com quem, quando, onde, em que condições e com que consequências (CASTANHEIRA; GREEN; DIXON, 2007). Segundo as autoras, a análise desses aspectos possibilita a identificação de padrões interacionais que, com o passar do tempo, podem se tornar invisíveis aos membros do grupo, mas que funcionam como princípios que orientam as práticas escolares desenvolvidas em sala de aula.

De acordo com Gee e Green (1998, apud AMARAL; MORTIMER, 2006), a perspectiva etnográfica interacional é interpretativa dos processos coletivos de aprendizagem, e atribui à linguagem e ao discurso um papel fundamental na construção de significados na sala de aula. Amaral e Mortimer (2006) discutem ainda que a etnografia interacional propõe estratégias de organização de dados em níveis múltiplos, e que os contextos observados em sala de aula podem ser organizados em mapas - estratégia que permite a contextualização dos enunciados produzidos na sala de aula orientando a escolha de episódios relevantes para a análise dos dados.

Sendo assim, a pesquisa foi realizada com alunos de uma turma do $1^{\circ}$ ano do Ensino Médio de uma Escola Pública de Pernambuco, com faixa etária entre 15 e 17 anos, na qual havia sido abordado conteúdo químico que versa sobre os conceitos de ácidos e bases. No total, 30 alunos da turma participaram das atividades propostas, mas, apenas 12 alunos foram selecionados para análise. Os critérios para a escolha desses sujeitos da pesquisa foram: maior participação na intervenção didática, menor desempenho em aulas de Química, e bom nível de influência que cada um desses indivíduos exercia sobre os demais. Foram feitas observações em sala de aula, com gravação em vídeo, e os momentos relevantes foram transcritos e analisados buscando-se descrever e interpretar a dinâmica interativa do discurso estabelecido na sala de aula. Consideramos fundamentais, para a análise dos resultados, os trechos de vídeo nos quais foram verificados momentos de maior grau de interação entre os participantes da pesquisa, assim como os momentos nos quais o conhecimento sobre o conteúdo desenvolvido foi discutido, em cada atividade proposta. A professora que orientou os trabalhos dos alunos nos grupos é uma das autoras deste trabalho.

A investigação consistiu de dois momentos principais. No primeiro momento, aplicamos um questionário para levantamento de concepções e perfis dos sujeitos envolvidos na pesquisa. No segundo momento, foram acompanhadas, com observação e gravação, cinco aulas propostas para o ensino de ácidos e bases, nas quais foram desenvolvidas diferentes atividades didáticas. Com isso, foi possível obter os dados necessários à análise da formação dos grupos, das interações em sala de aula e sua relação com cada uma das atividades propostas, considerando os objetivos da pesquisa. Na primeira aula da sequência, todos os alunos da sala formaram grupos de duas formas distintas: espontânea (ES), ou seja, os indivíduos decidiram entre si os parceiros; e por meio de dinâmicas, em que a escolha dos participantes do grupo foi feita de forma aleatória (AL), e interesses pessoais não foram considerados. Todos os alunos, em seus grupos formados, participaram de todas as aulas e atividades; o objetivo era permitir que a pesquisa estivesse inserida num ambiente natural de modo que os alunos selecionados para a pesquisa, participantes de dois grupos (ES e AL), não se sentissem diferentes dos demais. Em momentos de aula expositiva, o trabalho foi voltado para o grande grupo, com a participação indistinta de todos os alunos da sala. Na pesquisa, a análise foi 
O papel das interações sociais e de atividades ...

focada na dinâmica interativa ocorrida entre os participantes dos grupos quando realizando as atividades propostas. As atividades consistiram de leitura de texto sobre ácidos e bases, uma atividade experimental e a realização de um jogo didático, elaborados pela professora com base nas ideias de Duarte (2003), Gaspar e Monteiro (2005) e Arce (2004). Todas essas atividades foram analisadas com a intenção de se verificarem diferentes modos de interação proporcionados por meio de diferentes atividades didáticas. Para este trabalho, apresentaremos a análise feita para as interações ocorridas durante a atividade experimental.

Com base em uma metodologia voltada para um processo sociointeracionista de ensino-aprendizagem, as aulas introdutórias sobre ácidos e bases apresentaram o conteúdo de forma contextualizada, investigando os conhecimentos prévios dos alunos e instigando-os à compreensão. A professora abordou os conceitos a partir da identificação dessas substâncias no cotidiano, já que os ácidos e bases estão presentes no dia a dia e suas características são pouco discutidas como aspecto relevante para a compreensão das mais diversas substâncias e reações químicas. A organização das aulas envolveu a formação de pequenos grupos de seis membros cada. Os alunos tiveram oportunidade de discutir entre eles, quase sempre sem a interferência da professora, sobre os aspectos relacionados aos ácidos e bases.

\section{Análise dos dados}

Para a análise dos dados, foram feitos recortes nos discursos promovidos em sala de aula, uma vez que não objetivamos uma análise discursiva ampla. Os trechos de transcrição coletados, ou seja, os episódios, foram extraídos considerando a sua relevância para a pesquisa, e forneceram subsídios para a análise dos dados. Um episódio pode ser definido como um conjunto de enunciados que cria um contexto para a emergência de um determinado significado ou vários (AMARAL; MORTIMER, 2006, p. 257). Nesta pesquisa, foi dada relevância aos momentos em que identificamos aspectos importantes para as interações constituídas nos grupos e para a aprendizagem conceitual. Fizemos a análise dos dados a partir de uma estrutura proposta por Mortimer e Scott $(2002,2003)$ para análise, compreensão e discussão da dinâmica discursiva em sala de aula. A partir da estrutura analítica proposta, identificamos tipos de abordagem comunicativa e padrões de interação que foram estabelecidos em sala de aula (MORTIMER; SCOTT, 2003; MEHAN, 1979 apud AMARAL; MORTIMER, 2006).

O conceito de abordagem comunicativa é central na estrutura analítica proposta por Mortimer e Scott (2003), fornecendo a perspectiva sobre como o professor trabalha as intenções e o conteúdo de ensino por meio das diferentes intervenções pedagógicas que resultam em diferentes padrões de interação. Desse modo, os autores identificaram quatro classes de abordagem comunicativa, que são definidas por meio da caracterização do discurso entre professor e alunos ou entre alunos em termos de duas dimensões: discurso dialógico ou de autoridade; discurso interativo ou não interativo (MORTIMER; SCOT'T, 2003).

No discurso dialógico o professor considera o que o aluno tem a dizer do ponto de vista do próprio aluno; mais de uma "voz" é considerada e há uma interanimação de ideias. No discurso de autoridade, o professor considera o que o aluno tem a dizer apenas do ponto de vista do discurso científico escolar que está sendo construído. Apenas uma "voz" é ouvida, e não há interanimação de ideias. Tais aspectos da abordagem comunicativa estão relacionados 
Nascimento, J. M.; Amaral, E. M. R.

com a segunda dimensão do discurso, cuja distinção está entre o discurso interativo, aquele que ocorre com a participação de mais de uma pessoa, e o discurso não interativo, que ocorre com a participação de uma única pessoa. A combinação entre essas abordagens encontra-se sintetizada abaixo:

3/4 Interativo/dialógico: professor e estudantes exploram ideias, formulam perguntas autênticas e oferecem, consideram e trabalham diferentes pontos de vista.

3/4 Não interativo/dialógico: o professor reconsidera, na sua fala, vários pontos de vista, destacando similaridades e diferenças.

3/4 Interativo/de autoridade: o professor geralmente conduz os estudantes por meio de uma sequência de perguntas e respostas, com o objetivo de chegar a um ponto de vista específico.

3/4 Não interativo/de autoridade: o professor apresenta um ponto de vista específico.

Em relação aos padrões de interação em sala de aula, a análise dos dados da pesquisa tomou por base a descrição feita por Mehan (1979 apud AMARAL; MORTIMER, 2006). O padrão mais comum são as tríades I-R-A (Iniciação do professor, Resposta do aluno, Avaliação do professor), mas outros também podem ser observados, como as cadeias não triádicas identificadas quando o professor apresenta um feedback $(\mathrm{F})$ ou um prosseguimento $(\mathrm{P})$ à fala do aluno, com o objetivo de sustentar sua produção discursiva e dar continuidade à interação: I-R-P-R-P... ou I-R-F-R-F... Essas cadeias podem ser abertas, quando não apresentam uma avaliação ao seu final, ou fechadas, quando apresentam (AMARAL; MORTIMER, 2006). As categorias para caracterização de padrões de interação em sala de aula (MEHAN, 1979 apud AMARAL; MORTIMER, 2006) encontram-se descritas no Quadro 1.

Quadro 1. Categorias para a caracterização de padrões de interação em sala de aula

\begin{tabular}{|c|c|}
\hline & Tipos de iniciação \\
\hline Iniciação de escolha - le & O retorno deve ser para concordar ou discordar \\
\hline Iniciação de produto - If & O retorno deverá ser uma resposta factual \\
\hline Iniciação de processo - Ip & O retorno representa uma opinião ou interpretação \\
\hline \multirow[t]{2}{*}{ Iniciação de metaprocesso - Im } & O retorno é um reflexão sobre o processo \\
\hline & Tipos de respostas \\
\hline Relativa à iniciação - R & $\begin{array}{l}\text { Reflete o tipo de iniciação feita, podendo ser uma escolha, uma resposta } \\
\text { factual, uma opinião ou interpretação, ou uma reflexão sobre o processo. }\end{array}$ \\
\hline \multirow[t]{2}{*}{ Relativa à avaliação } & $\begin{array}{l}\text { Resposta completa } \\
\text { Resposta parcialmente completa } \\
\text { Resposta incorreta ou assimétrica } \\
\text { Ausência de resposta }\end{array}$ \\
\hline & Tipos de avaliação e prosseguimento \\
\hline Avaliação positiva -A & Finaliza a sequência \\
\hline Prosseguimento - $\mathrm{P}$ & $\begin{array}{l}\text { Avaliação negativa } \\
\text { Repetição da iniciação } \\
\text { Simplificação da iniciação } \\
\text { Outros }\end{array}$ \\
\hline
\end{tabular}

Fonte: Amaral; Mortimer (2006, p. 255). 
O papel das interações sociais e de atividades ...

Para análise das atividades didáticas propostas, foram consideradas algumas proposições propostas por Leontiev (2001) para caracterização das atividades. Sendo assim, na análise das atividades, consideramos como aspectos fundamentais: a necessidade da atividade, consistindo essencialmente em seu objetivo de aprendizagem; as tarefas propostas, consistindo nos objetivos da própria atividade; as ações desempenhadas pelos membros do grupo em torno da resolução das tarefas; e as operações para realização das ações que consistem no modo de execução para as ações. De uma forma geral, a análise consistiu em verificar se os objetivos de aprendizagem foram alcançados por meio das tarefas, ações e operações realizadas. Entretanto, ressaltamos que, neste trabalho, apresentaremos apenas a análise para a atividade experimental.

\section{Resultados e discussão}

Durante a aula, os alunos, em seus grupos, participaram de um experimento com o objetivo de identificar e classificar as substâncias como ácidas ou básicas (Quadro 2). A escolha por esse tipo de atividade se deu pela relação direta da mesma com o conteúdo estudado, e por consistir numa ferramenta capaz de dar suporte a uma prática coletiva de ensinoaprendizagem. Em geral, os experimentos tendem a estimular uma aprendizagem prazerosa, uma vez que utilizam um ambiente diferente da sala de aula e produzem resultados variados. São atividades que apresentam desafios cognitivos que motivam a participação dos alunos de todas as idades. Além disso, os alunos também costumam atribuir à experimentação um caráter motivador, lúdico, essencialmente vinculado aos sentidos (GIORDAN, 1999, 2003). A experimentação possui, ainda, vários objetivos prescritos, tais como: estimular a observação, promover métodos de pensamento científico simples e de senso comum, desenvolver habilidades manipulativas, treinar a resolução de problemas, esclarecer a teoria e promover a sua compreensão, verificar fatos e princípios estudados anteriormente, motivar e manter o interesse na matéria, e tornar os fenômenos mais reais por meio da experiência (HODSON, 1998, p. 630 apud GALIAZZI et al., 2001).

Assim, os alunos, coletivamente, organizaram seus materiais nas bancadas, registrando por escrito os resultados. A partir das suas observações, eles discutiram entre si explicações necessárias para a posterior elaboração de um relatório (Quadro 2).

A atividade experimental foi realizada no laboratório da escola e a caracterização desta atividade está no Quadro 3. Para isso, a escola dispõe de bancadas, mesas, vidraria e reagentes, tais como indicadores de ácido-base, necessários à aplicação da atividade. Apesar dos recursos disponíveis, os alunos não estavam habituados a frequentar o laboratório em anos anteriores. A frequência, portanto, se deu inicialmente a partir das aulas de Química no $1^{\circ}$ ano do Ensino Médio. Salientamos que as práticas experimentais em grupos fazem parte do modo de trabalho da professora, autora da pesquisa.

A partir das gravações em vídeo e anotações de campo, observamos que, durante a atividade experimental, havia grande entusiasmo dos alunos, que permaneciam organizados nos grupos formados. O interesse e a curiosidade foram crescendo à medida que era possibilitada a contextualização dos conteúdos disciplinares anteriormente discutidos em sala de aula, tais como: a presença das funções químicas no dia a dia, bem como a discussão de aspectos como corrosão, agressão à saúde humana, entre outros. 
Nascimento, J. M.; Amaral, E. M. R.

Quadro 2. Mapa de eventos da aula 3

\begin{tabular}{|l|l|l|l|l|}
\hline $\begin{array}{c}\text { Tempo } \\
\mathbf{1 0 0} \text { min. }\end{array}$ & Atividades desenvolvidas & $\begin{array}{c}\text { Modo de } \\
\text { interações }\end{array}$ & \multicolumn{1}{|c|}{ Ações dos participantes } & \multicolumn{1}{c|}{$\begin{array}{c}\text { Conteúdos } \\
\text { explorados }\end{array}$} \\
\hline $\mathbf{1 5}$ min. & $\begin{array}{l}\text { Explicação do conteúdo da } \\
\text { aula. }\end{array}$ & $\begin{array}{l}\text { A professora explica o conteúdo } \\
\text { enquanto os alunos prestam } \\
\text { atenção fazendo pequenos } \\
\text { comentários e questionamentos. }\end{array}$ & $\begin{array}{l}\text { Identificação de } \\
\text { ácidos bases. } \\
\text { Indicadores de ácido } \\
\text { e base. } \\
\text { Determinação de pH. }\end{array}$ \\
\hline 15 min. & $\begin{array}{l}\text { Preparação dos reagentes. } \\
\text { Leitura e organização dos } \\
\text { procedimentos. } \\
\text { Divisão das tarefas no grupo. }\end{array}$ & Em grupos & $\begin{array}{l}\text { Os alunos preparam os materiais } \\
\text { e reagentes para a aula } \\
\text { experimental. }\end{array}$ & \\
\hline 70 min. & $\begin{array}{l}\text { Realização do experimento. } \\
\text { Em grupos }\end{array}$ & $\begin{array}{l}\text { Os alunos testam os reagentes } \\
\text { construindo uma escala de pH. }\end{array}$ & $\begin{array}{l}\text { Determinação da } \\
\text { Escala de pH }\end{array}$ \\
\hline
\end{tabular}

Fonte: Nascimento (2009).

Quadro 3. Caracterização da atividade experimental realizada na aula

\begin{tabular}{|l|l|}
\hline \multicolumn{2}{|c|}{ Caracterização da atividade } \\
\hline Atividade & Atividade experimental. \\
\hline Necessidade & $\begin{array}{l}\text { Identificar, por meio de indicadores, a presença de ácidos e bases nas substâncias } \\
\text { comuns ao dia a dia. }\end{array}$ \\
\hline Tarefas & Construir uma tabela de pH a partir de substâncias comuns ao dia a dia. \\
\hline Ações & $\begin{array}{l}\text { Preparação do indicador. } \\
\text { Identificação das substâncias. } \\
\text { Determinação do pH }\end{array}$ \\
\hline Operações & Leitura do roteiro. \\
& Preparação do material reagente. \\
& Distribuição do material reagente entre os participantes. \\
& Discussão no grupo a partir de questões. \\
& Escolha do aluno que fará o relatório. \\
& Transcrição dos dados para o relatório.
\end{tabular}

Fonte: Leontiev (1978)

Essa articulação foi promovida pela proposição de operações, como: leitura de pequeno texto, manuseio de material, constatação de diferentes cores para ácidos e bases, anotações acerca do que estava sendo observado, e a síntese de ideias para elaboração do relatório. Desse modo, a atividade experimental produziu resultados mais relevantes. $\mathrm{O}$ envolvimento dos integrantes, em ambos os grupos, em torno da realização das operações, resultou numa maior aprendizagem, e esse aspecto foi verificado com base na discussão nos grupos, sobre o conteúdo estudado que será analisado a seguir e, também, após a entrega dos relatórios. 
O papel das interações sociais e de atividades ...

\section{Análise das interações discursivas na aula}

A análise da discussão entre os alunos nos dois grupos, durante a atividade experimental, indica, a princípio, que os alunos, em ambos os grupos, não compreendiam exatamente o que deveriam fazer. Isso se deve ao fato de que, em anos anteriores, não haviam realizado aulas experimentais, conforme apontado anteriormente e, também, devido, muitas vezes, a uma concepção de trabalho prático relacionado apenas com o fazer, sem um compromisso com a reflexão sobre o que se faz. Nesse sentido, pressupõe-se que muitas atividades experimentais apenas estimulam a execução das ações, sem que os alunos compreendam por que estão executando as mesmas. Para melhor compreensão do que deveria ser feito, os alunos receberam um roteiro semiestruturado dos procedimentos a serem seguidos. Desse modo, inicialmente, foi feita uma análise para o grupo ES e, em seguida, para o grupo AL, buscando identificar o desempenho dos alunos nos grupos formados com diferentes estratégias.

\section{Análise do grupo ES}

O episódio 1.1 ilustra aspectos discursivos do grupo ES quando os grupos, em suas bancadas e após a exposição dos conteúdos pela professora, preparavam os reagentes para iniciar a experimentação (Quadro 4).

No episódio 1.1, observamos que, inicialmente, os alunos não compreendiam os procedimentos que deveriam ser adotados (turnos 1 e 3). A aluna A3 conduzia os demais colegas de modo que as operações fossem realizadas adequadamente. Sua preocupação com a organização das operações influenciou significativamente os demais participantes do grupo, permitindo

Quadro 4. Episódio 1.1 Preparação dos reagentes e organização dos trabalhos/grupo ES

\begin{tabular}{|l|l|l|}
\hline \multicolumn{1}{|c|}{ Episódios/Turnos/Sujeitos } & \multicolumn{2}{|c|}{ Categorização dos aspectos discursivos } \\
\hline $\begin{array}{l}\text { Episódio 1.1 Preparação dos reagentes e } \\
\text { organização dos trabalhos }\end{array}$ & \multicolumn{1}{|c|}{ Padrões de Interação } & \multicolumn{1}{|c|}{$\begin{array}{c}\text { Abordagem } \\
\text { comunicativa }\end{array}$} \\
\hline 1. A2: Não é pra misturar nada não? & Iniciação de escolha - le & \\
\hline 2. A3: Não. & Resposta - R & \multirow{2}{*}{ Interativa/ dialógica } \\
\hline 3. A2: E é pra fazer o quê? & Prosseguimento - P \\
\hline $\begin{array}{l}\text { 4. A3: A professora explicou. Olha aqui o roteiro do que é } \\
\text { pra fazer. Fica com esses dois tubos. Esse é de } \\
\text { detergente e esse suco de abacaxi. }\end{array}$ & Avaliação - A \\
\hline 5. A5: Eu fico com esse do creme de leite. & Prosseguimento - P \\
\hline 6. A3: Primeiro a gente lê. Ninguém faz nada agora. & Resposta - R \\
\hline 7. A2: Alguém lê [...] É melhor. & Prosseguimento - P \\
\hline 8. A1: Me dá o vinagre. & Resposta - R \\
\hline 9. A6: É pra anotar alguma coisa? & Iniciação de produto - If \\
\hline $\begin{array}{l}\text { 10. A3: Cada um vai anotando o seu no papel porque } \\
\text { tem que fazer um relatório. }\end{array}$ & Avaliação - A \\
\hline
\end{tabular}

Fonte: Nascimento (2009). 
que a atividade ocorresse de forma sistematizada. A capacidade de liderança da aluna A3 foi suficiente para promover interações que possibilitassem ao grupo atingir o objetivo, a partir da compreensão sobre as ações a serem realizadas. A apreensão dos conceitos por parte de alguns alunos no grupo reforça a concepção vygotskiana de que os processos de aprendizado ocorrem na medida em que os indivíduos interatuam uns com os outros. A capacidade de liderança de alguns, a contribuição intelectual de outros, associadas à discussão sobre os conceitos recuperados da leitura nos textos didáticos, possibilitaram um avanço, em maior ou menor grau, do desenvolvimento cognitivo de cada indivíduo do grupo. A leitura do roteiro ajudou os alunos a se situarem quanto às ações a serem realizadas na atividade proposta (turno 4).

O episódio 1.2 ilustra alguns momentos de interações discursivas do grupo ES em torno da atividade experimental (Quadro 5).

A análise do episódio 1.2 permitiu verificar que, em relação ao grupo ES, a motivação pela atividade foi suficiente para envolver quase todos os alunos do grupo. Mesmo os alunos A4 e A5, que não participaram efetivamente de outras atividades durante a intervenção, participaram de forma significativa e produtiva na resolução da tarefa durante toda a atividade experimental (turnos 7, 10 e 18). À medida que as operações eram realizadas, as interações ocorriam de modo que possibilitassem a aprendizagem (turnos 5-6; 11-13; 15-20). Nas falas dos alunos, a troca de informações era frequente. $O$ grupo apresentou indícios de maior integração e produtividade entre seus membros, de modo que os objetivos de aprendizagem ocorressem de forma prazerosa. A discussão ficou focada em aspectos visíveis do experimento, mas consideramos que esta etapa é preliminar para a compreensão sobre substâncias indicadoras nos estudos de ácidos e bases.

\section{Análise do grupo AL}

O episódio 1.3 aborda o trecho da discussão promovida pelo grupo AL quando este preparava os reagentes para realizar o experimento (Quadro 6).

O episódio 1.3 relata alguns pontos do discurso inicial do grupo AL. Assim como no grupo ES, houve certa inquietação, por parte dos integrantes do grupo, quanto aos procedimentos que deveriam ser realizados (turnos 1-2). A liderança do grupo ficou com o aluno A9, que conduzia as operações para a realização da tarefa. O grupo também apresentou maior envolvimento na atividade do que usualmente demonstrava, e essa constatação parece positiva, uma vez que se trata de um agrupamento aleatório de pessoas. Nesse sentido, podemos sugerir que as ações, quando realizadas na direção de objetivos bem definidos, criam possibilidade de interações entre indivíduos.

O episódio 1.4 ilustra parte da discussão promovida pelo grupo na realização do experimento (Quadro 7).

Apesar de haver interação, na discussão de algumas ideias, verificamos um diálogo limitado entre os membros do grupo, que parece ter concentrado seus esforços apenas em torno da resolução das tarefas. Observamos que havia motivação suficiente para a atividade na medida em que esta acontecia. Assim como no grupo ES, os alunos do grupo AL também não realizavam aulas experimentais em anos anteriores, e o interesse pela resolução das tarefas permitiu que a aprendizagem ocorresse de forma eficaz (turnos 4-6). O grupo AL realizou a tarefa em um tempo mais curto do que o grupo ES. 
O papel das interações sociais e de atividades ...

Quadro 5. Episódio 1.2 Realização do experimento/grupo ES

\begin{tabular}{|c|c|c|}
\hline Episódios/Turnos/Sujeitos & Categorização dos aspec & tos discursivos \\
\hline Episódio 1.2 - Realização do experimento & Padrões de Interação & $\begin{array}{l}\text { Abordagem } \\
\text { comunicativa }\end{array}$ \\
\hline $\begin{array}{l}\text { 1. A1:Mas eu já sei que vinagre é ácido. Já pode } \\
\text { colocar no papel? }\end{array}$ & Iniciação de escolha - le & \multirow{19}{*}{ Interativa/ dialógica } \\
\hline $\begin{array}{l}\text { 2. A3: Claro que não... Primeiro tem que prepararo } \\
\text { suco de feijão com sabão em pó e o outro. Cadê? É } \\
\text { com suco de limão. }\end{array}$ & Resposta-R & \\
\hline 3. A1: Olha aqui. E agora? Faz o quê? & Prosseguimento - $\mathrm{P}$ & \\
\hline $\begin{array}{l}\text { 4. A3: Depois a gente vai comparar as cores e } \\
\text { colocar na ordem. Vamos preparar logo o suco de } \\
\text { feijão, depois a gente vê isso. Vou perguntar de novo. }\end{array}$ & Resposta-R & \\
\hline 5. A6: Olha a cor que ficou. Por que hein? & Iniciação de metaprocesso - Im & \\
\hline $\begin{array}{l}\text { 6. A3: A água do feijão é neutra. Eu anotei aqui. } \\
\text { Serve como indicador. Tem no livro. Muda de cor se } \\
\text { colocar um ácido ou uma base dentro. }\end{array}$ & Resposta-R & \\
\hline $\begin{array}{l}\text { 7. A4: Olha a cor que ficou o meu. Azul escuro. Me } \\
\text { dá uma fita aí. Vê aí na caixinha qual é o pH? }\end{array}$ & Prosseguimento - $\mathrm{P}$ & \\
\hline 8. A2: Acho que é 11 ou 12. Vê aí. & Resposta-R & \\
\hline 9. A1: Cadê? É 11. É de quê? & Iniciação de produto - IF & \\
\hline 10. A4: Água com sabão em pasta. & Resposta-R & \\
\hline 11. A2: Quando fica nessa cor é ácido ou base? & Iniciação de produto- IF & \\
\hline 12. A3: Ácido é de 0 a 6. Olha aqui. & Resposta-R & \\
\hline 13. A2: Ah! Então é base. [...] & Prosseguimento - $\mathrm{P}$ & \\
\hline 14. A3: O meu não mudou de cor não. & Iniciação de metaprocesso - Im & \\
\hline 15.A1: Ficasse com o quê? & Resposta-R & \\
\hline $\begin{array}{l}\text { 16. A3: Leite e suco de laranja. O que não mudou a } \\
\text { cor foi o do leite. }\end{array}$ & Prosseguimento $-\mathrm{P}$ & \\
\hline $\begin{array}{l}\text { 17. A5: Então coloca o que? Esse aqui também não } \\
\text { mudou nada. É o do creme de leite. }\end{array}$ & Iniciação de metaprocesso - Im & \\
\hline 18. A3: Acho que é neutro. $p H$ 7. Olha aqui. & Resposta-R & \\
\hline $\begin{array}{l}\text { 19. A1: É. Olha aqui. Quando não muda de cor é } \\
\text { neutro. (Diz apontando para o livro) Me deixa vero } \\
\text { meu... É ácido. }\end{array}$ & Avaliação-A & \\
\hline
\end{tabular}

Fonte: Nascimento (2009).

Os resultados da aula nos motivaram a refletir sobre a utilização de atividades experimentais no ensino de Química. Quanto à dinâmica interativa analisada, ocorreu dentro dos grupos sem a participação efetiva da professora. Padrões de interação com cadeias não triádicas foram observados nos episódios da aula, nos quais os prosseguimentos $(\mathrm{P})$ eram encandeados pelos próprios alunos que questionavam os procedimentos (episódios 1.1 e 1.3 ) e/ou contribuíam para a construção das aprendizagens dentro dos grupos (episódios 1.2 e 1.4). 
Nascimento, J. M.; Amaral, E. M. R.

Quadro 6. Episódio 1.3 Preparação dos reagentes e organização dos trabalhos/grupo AL

\begin{tabular}{|c|c|c|}
\hline Episódios/Turnos/Sujeitos & Categorização dos as & ctos discursivos \\
\hline $\begin{array}{l}\text { Episódio 1.3 Preparação dos reagentes e organização } \\
\text { dos trabalhos }\end{array}$ & Padrões de Interação & $\begin{array}{l}\text { Abordagem } \\
\text { comunicativa }\end{array}$ \\
\hline 1. A10: Vocês entenderam o que é pra fazer? & Iniciação de escolha - le & \multirow{8}{*}{ Interativa/ dialógica } \\
\hline 2. A7: Tudo não. [...] & Resposta - R & \\
\hline $\begin{array}{l}\text { 6. A9: Vamos ler. Se agente não entender a gente } \\
\text { pergunta. }\end{array}$ & Prosseguimento - $\mathrm{P}$ & \\
\hline $\begin{array}{l}\text { 7. A11: Primeiro tem que preparar o suco do limão com o } \\
\text { suco do feijão. }\end{array}$ & Iniciação de escolha - le & \\
\hline 8. A9: É. $[\ldots]$ & Resposta-R & \\
\hline 12. A9: Faz o outro suco. É o de sabão em pó com feijão. & Prosseguimento - $\mathrm{P}$ & \\
\hline 13. A12: Me dá que eu faço. & Resposta - R & \\
\hline $\begin{array}{l}\text { 14. A9: Tem que ir anotando tudo numa folha. } \\
\text { A professora vai querer relatório depois. }\end{array}$ & Avaliação - A & \\
\hline
\end{tabular}

Fonte: Nascimento (2009).

Quadro 7. Episódio 1.4 Realização do experimento/ grupo AL

\begin{tabular}{|l|l|l|}
\hline \multicolumn{1}{|c|}{ Episódios/Turnos/Sujeitos } & \multicolumn{2}{|c|}{ Categorização dos aspectos discursivos } \\
\hline Episódio 1.4 - Realização do experimento & \multicolumn{1}{|c|}{ Padrões de Interação } & \multicolumn{1}{|c|}{$\begin{array}{c}\text { Abordagem } \\
\text { comunicativa }\end{array}$} \\
\cline { 1 - 2 } 1. A11: Depois disso faz o quê? [...] & Iniciação de produto - If & \\
\cline { 1 - 2 } $\begin{array}{l}\text { 3. A11: É pra molhar o papel nas substâncias e ver na } \\
\text { caixinha. A gente anota o número e depois diz se é ácido } \\
\text { ou base. }\end{array}$ & Resposta - R \\
\cline { 1 - 2 } 4. A7: Interessante, não é? & Iniciação de escolha - le & \\
\cline { 1 - 2 } 5. A11: Gostei disso. Melhor do que aula normal, não é? & $\begin{array}{l}\text { Resposta - R } \\
\text { Iniciação de escolha - le }\end{array}$ & \\
\cline { 1 - 2 } 6. A9: É. & Avaliação - A \\
\hline
\end{tabular}

Fonte: Nascimento (2009).

Nos episódios analisados, as discussões ocorreram de forma interativa e numa abordagem dialógica e, dessa maneira, durante a realização do experimento foi fundamental a contribuição dos vários pontos de vista colocados pelos alunos para que a necessidade da atividade fosse satisfeita. Os resultados sugerem que promover uma maior proximidade dos alunos em sala de aula poderá facilitar a realização de tarefas e promover um diálogo mais frutífero em torno do conteúdo. 
O papel das interações sociais e de atividades ...

\section{Considerações finais}

A partir da análise das aulas, observamos que os alunos construíram significados para parte dos conceitos abordados sobre ácidos e bases apresentados, e que essa construção tem relação com a formação e constituição dos grupos organizados na sala de aula. Os dados encontrados sugerem que as interações aluno-aluno e o modo como esses grupos operavam determinou a eficácia da atividade realizada por eles, já que estas foram estruturadas a partir de substâncias utilizadas pelos próprios alunos cotidianamente.

Esperava-se que os sujeitos agrupados pela afinidade pessoal apresentassem maior eficácia em realizar as tarefas propostas por se caracterizarem como um grupo de indivíduos mais aberto ao diálogo e capacidade de interagir. Nesse sentido, os resultados indicaram relações significativas entre afinidade e aprendizagem no trabalho em grupo, nas condições em que a pesquisa foi conduzida. A afinidade entre os membros de cada grupo pode ser importante para os resultados apresentados por cada um. Acerca das atividades, nossas considerações supõem que diferentes operações caracterizaram diferentes ritmos de aprendizagem, e que a prática coletiva das atividades didáticas tende a suprir algumas das necessidades associadas à aprendizagem, resultando em um processo mais dinâmico. Ao professor, cabe promover ações facilitadoras do desenvolvimento cognitivo de cada aluno no contexto da coletividade e, para isso, utilizar atividades em grupo pode se constituir uma ferramenta eficaz.

$\mathrm{Na}$ nossa análise, verificamos diferenças significativas nas interações ocorridas durante a atividade proposta, tais como: entusiasmo, integração efetiva de alunos menos participativos nas aulas anteriores, assim como interações prazerosas dos indivíduos, em ambos os grupos. Isso parece ser devido ao fato de que a natureza do conteúdo abordado tem significativa relevância na vida cotidiana dos alunos e o formato da atividade proporcionou interações efetivas entre alunos. Essas características observadas na atividade experimental favoreceram a reflexão sobre o planejamento e execução desse tipo de atividade, no sentido de contribuir para a construção de novas aprendizagens. Aspectos como a natureza das ações propostas e a reflexão sobre as mesmas parecem fundamentais para promover o interesse e diálogo entre alunos ao longo da atividade.

A análise das falas dos alunos na atividade realizada em sala de aula identificou, com maior clareza, as intenções da professora ao apresentar o conteúdo conceitual de maneira a promover interações discursivas, enfatizando que a participação do aluno é fundamental. Além disso, a exploração de ideias envolvidas nas interações aluno/aluno possibilitou, à professora, considerar diferentes pontos de vista na discussão dos conceitos em sala de aula. Os padrões de interação estabelecidos nos trabalhos em grupo apresentam semelhanças com aqueles encontrados na sala de aula, e apontam para: a identificação da capacidade de liderança de alguns alunos, a participação efetiva de outros, e, também, para os diferentes papeis que cada um pode desempenhar no processo de construção do conhecimento na discussão em sala de aula. Em resumo, os nossos resultados nos levam a ratificar que as interações constituídas em sala de aula têm lugar relevante no processo de ensino-aprendizagem. É na troca com outros sujeitos com diferentes formas de pensar e agir, assim como diferentes níveis de elaboração conceitual, que os conceitos vão sendo formados. É por meio da atividade que esses conceitos vão sendo socialmente construídos. 
Nascimento, J. M.; Amaral, E. M. R.

\section{Referências}

AMARAL, E. M. R.; MORTIMER, E. F. Uma metodologia para análise da dinâmica entre zonas de um perfil conceitual no discurso da sala de aula. In: SANTOS, F. M. T.; GRECCA, I. M. (Org.). A pesquisa em ensino de ciências no Brasil e suas metodologias. Ijuí: Editora Unijuí, 2006. p. 239-296.

ANDRADE, D. R. de. O grupo como o entende Bauleo. In: BAREMBLITT, G. Grupos, teoria e técnica. Rio de Janeiro: Graal, 1986. p. 159-168.

ARCE, A. O jogo e o desenvolvimento infantil na teoria da atividade e no pensamento educacional de Friedrich Froebel. Cadernos Cedes, Campinas, v. 24, n. 62, p. 9-25, abr. 2004. Disponível em: < http://www.scielo.br/pdf/ccedes/v24n62/20089.pdf>. Acesso em: 9 mar. 2009.

CASTANHEIRA, M. L.; GREEN, J. L.; DIXON, C. N. Práticas de letramento em sala de aula: uma análise de ações letradas como construção social. Revista Portuguesa de Educação, Braga, v.20, n. 2, p. 7-38, 2007. Disponível em: <http:// www.scielo.oces.mctes.pt/pdf/rpe/v20n2/v20n2a02.pdf>. Acesso em: 9 mar. 2009.

CEDRO, W. L. O espaço de aprendizagem e a atividade de ensino: o clube de matemática. 2004. 158 f. Dissertação (Mestrado em Educação) - Faculdade de Educação, Universidade de São Paulo, São Paulo, 2004. Disponível em: <http://www.teses.usp.br/ teses/disponiveis/48/48134/tde-21062005-104453/pt-br.php>. Acesso em: 14 jan. 2008.

DUARTE, N. A teoria da atividade como uma abordagem para a pesquisa em educação. Perspectiva, Florianópolis, v. 21, n. 2, p. 229-301, jul./dez. 2003. Disponível em: <http:// www.ger.ufsc.br/index.php/perspectiva/article/download/9646/8881>. Acesso em: 10 ago. 2009.

GALIAZZI, M. C. et al. Objetivos das atividades experimentais no ensino médio: a pesquisa coletiva como modo de formação de professores de ciências. Ciência \& Educação, Bauru, v. 7, n. 2, p. 249-263, 2001. Disponível em: <http://www.scielo.br/pdf/ ciedu/v7n2/08.pdf>. Acesso em: 21 jul. 2009.

GASPAR, A.; MONTEIRO, I. C. C. Atividades experimentais de demonstrações em sala de aula: uma análise segundo o referencial da teoria de Vygotsky. Investigações em Ensino de Ciências, Porto Alegre, v. 10, n. 2, p. 227-254, 2005. Disponível em: <www.if.ufrgs.br/ ienci/artigos/Artigo_ID130/v10_n2_a2005.pdf>. . Acesso em: 11 mar. 2009.

GIORDAN, M. O papel da experimentação no ensino de ciências. Química Nova na Escola, São Paulo, n. 10, p. 43-49, nov. 1999. Disponível em: <http://qnesc.sbq.org.br/ online/qnesc10/pesquisa.pdf>. Acesso em: 12 ago. 2009.

. Experimentação por simulação. Textos LAPEQ, São Paulo, n. 8, junho 2003. Disponível em: <http://quimica.fe.usp.br/textos/educ/pdf/experimentacao.pdf > . Acesso em: 12 ago. 2009. 
O papel das interações sociais e de atividades ...

LEONTIEV, A. N. Sobre o desenvolvimento histórico da consciência. In:

O desenvolvimento do psiquismo. Lisboa: Horizonte Universitário, 1978. p. 89-142.

The problem of activity in psychology. In: WERTSCH, J. V. (Ed.). The concept

of activity in Soviet psychology. New York: M. E. Sharpe, 1979. p. 37-71. Disponível em: $<$ http://people.ucsc.edu/ gwells/Files/Courses_Folder/documents/

LeontievProblemofactivity.pdf>. Acesso em: 14 jan. 2008.

Actividad, conciencia, personalidad. Habana: Pueblo y Educación, 1983.

In: VIGOTSKI, L. S.; LURIA, A. R.; LEONTIEV, A. N. Linguagem,

desenvolvimento e aprendizagem. São Paulo: Ícone, 2001. p. 59-83

LIBÂNEO, J. C. A didática e a aprendizagem do pensar e do aprender: a teoria histórico-cultural da atividade e a contribuição de Vasili Davydov. Revista Brasileira de

Educação, Rio de Janeiro, n. 27, p. 5-24, 2004. Disponível em: < http://www.scielo.br/ pdf/rbedu/n27/n27a01.pdf>. Acesso em: 14 jan. 2008.

MORTIMER, E. F.; SCOTT, P. Atividade discursiva nas salas de aula de ciências: uma ferramenta sociocultural para analisar e planejar o ensino. Investigações em Ensino de Ciências, Porto Alegre, v. 7, n. 3, p. 283-306, 2002. Disponível em: <http://

www.if.ufrgs.br/ienci/artigos/Artigo_ID94/v7_n3_a2002>. Acesso em: 6 maio 2009.

MORTIMER, E.F.; SCOT'T, P.H. Meaning making in secondary science classrooms. Maidenhead: Open University Press, 2003.

MOURA, M. O. A atividade de ensino como ação formadora. In: CASTRO, A. D. de; CARVALHO, A. M. de (Org.). Ensinar a ensinar: didática para a escola fundamental e média. São Paulo: Pioneira Thomson Learning, 2002. p.143-162.

NASCIMENTO, J. M. O papel das interações sociais e atividades no processo de ensino-aprendizagem em aulas de química. 2009. 124 f. Dissertação (Mestrado em Ensino de Ciências) - Departamento de Educação, Universidade Federal Rural de Pernambuco, Recife, 2009.

NÚÑEZ, I. B.; FARIA, T. C. L. A aprendizagem na perspectiva de Jean Piaget. In: NÚÑEZ, I. B.; RAMALHO, B. L. (Org.). Fundamentos do ensino-aprendizagem das ciências naturais e da matemática: o novo ensino médio. Porto Alegre: Sulina, 2004. p. 43-50.

OLIVEIRA, M. K. Vygotsky: aprendizado e desenvolvimento, um processo sócio histórico. São Paulo: Scipione, 2003.

PINO, A. O social e o cultural na obra de Vigotski. Educação e Sociedade, São Paulo, v. 21, n. 71, p. 45-78, 2000. Disponível em: <http://www.scielo.br/pdf/es/v21n71/ a03v2171.pdf>. Acesso em: 5 jun. 2006. 
Nascimento, J. M.; Amaral, E. M. R.

SFORNI, M. S. de F. Aprendizagem conceitual e organização do ensino: contribuições da teoria da atividade. 2003. 166p. Tese (Doutorado em Educação) - Faculdade de Educação, Universidade de São Paulo, São Paulo, 2003.

TURRA, F. R.; SANTOS, F. E. G. Manual metodológico: organização social. Brasilia: Serviço Nacional de Aprendizagem do Cooperativismo, 2002. Disponível em: <http:// www.turismocooperativo.coop.br/Apostilas/Manual_Metodologico.pdf $>$. Acesso em: 14 jan. 2008.

VYGOTSKY, L. A formação social da mente: o desenvolvimento dos processos psicológicos superiores. São Paulo: Martins Fontes, 2007.

Artigo recebido em 03/11/2011. Aceito em 26/04/2012. 